\title{
A CHRONIC PAIN: INFLAMMATION-DEPENDENT CHEMORECEPTOR ADAPTATION IN RAT CAROTID BODY
}

\author{
X. Liu ${ }^{1}$, L. He ${ }^{1}$, B. Dinger ${ }^{1}$, C. Gonzalez ${ }^{2}$, L. Stensaas ${ }^{1}$, and S. Fidone ${ }^{1}$ \\ ${ }^{1}$ Department of Physiology, University of Utah School of Medicine, Salt Lake City, UT, USA \\ 2 Departamento de Bioquímica y Biología Molecular y Fisiología, Instituto de Biología y Genética \\ Molecular y CIBER de Enfermedades Respiratorias, Universidad de Valladolid, Consejo Superior \\ de Investigaciones Científicas e Instituto Carlos III. Facultad de Medicina 47005 Valladolid, Spain
}

\section{Abstract}

Experiments in recent years have revealed labile electrophysiological and neurochemical phenotypes in primary afferent neurons exposed to specific stimulus conditions associated with the development of chronic pain. These studies collectively demonstrate that the mechanisms responsible for functional plasticity are primarily mediated by novel neuroimmune interactions involving circulating and resident immune cells and their secretory products, which together induce hyperexcitability in the primary sensory neurons. In another peripheral sensory modality, namely the arterial chemoreceptors, sustained stimulation in the form of chronic hypoxia $(\mathrm{CH})$ elicits increased chemoafferent excitability from the mammalian carotid body. Previous studies which focused on functional changes in oxygen-sensitive type I cells in this organ have only partially elucidated the molecular and cellular mechanisms which initiate and control this adaptive response. Recent studies in our laboratory indicate a unique role for the immune system in regulating the chemo-adaptive response of the carotid body to physiologically relevant levels of hypoxia.

\section{Keywords}

Cytokines; Macrophages; Hypoxia; Voltage-gated Sodium Channels; Neuroplasticity

\section{Introduction}

\begin{abstract}
Oxygen chemoreceptors in the carotid body continuously monitor arterial blood $P_{O_{2}}$ as part of a complex autonomic mechanism that matches lung ventilation and cardiac output to systemic tissue oxidative metabolism. Acute hypoxia excites oxygen-sensitive type I cells in carotid body and elevates impulse traffic in the carotid sinus nerve (CSN) which reflexly increases ventilation. Under controlled conditions, CSN responses to repeated acute hypoxic challenges are highly reproducible. However, a peculiar aspect of carotid body function is that following chronic hypoxia $(\mathrm{CH})$, chemoreceptor activity evoked by an acute challenge is substantially enhanced. This increased activity has been shown to underlie ventilatory
\end{abstract}

\footnotetext{
C 2011 Elsevier B.V. All rights reserved.

Corresponding author: Dr. Bruce Dinger, Department of Physiology, University of Utah School of Medicine, 420 Chipeta Way, Salt Lake City, UT, 84108-6500, USA, b.dinger@utah.edu, Office: 801 581-8488, Fax: 801 581-3476.

Publisher's Disclaimer: This is a PDF file of an unedited manuscript that has been accepted for publication. As a service to our customers we are providing this early version of the manuscript. The manuscript will undergo copyediting, typesetting, and review of the resulting proof before it is published in its final citable form. Please note that during the production process errors may be discovered which could affect the content, and all legal disclaimers that apply to the journal pertain.
} 
acclimatization to hypoxia (VAH), a phenomenon in mammals characterized by a gradual increase in ventilation which occurs over a period of days-to-weeks at high altitude and in hypobaric hypoxia (Powell et al. 1998). The cellular and molecular mechanisms underlying $\mathrm{CH}$-induced chemoreceptor adaptation are only partially understood. The current review highlights the role of unique neuroimmune mechanisms in the adaptive process. Available data suggest that chemoreceptor plasticity is analogous to adjustments induced in the peripheral nervous system during chronic inflammatory pain.

\section{The Carotid Body and Adaptation to Chronic Hypoxia}

The carotid body consists of integrated units of chemoreceptor, neural, glial and vascular cells surrounded by connective tissue, which collectively constitute a highly adaptive chemosensory organ. Stimulus transduction occurs in paracrine type I (chemoreceptor) cells which release multiple neuro-active agents in response to hypoxia, hypercapnia and acidosis. Primary afferent neurons in the petrosal ganglia (PG) project axons through the carotid sinus nerve (CSN) to form synaptic terminals on type I cells, while glial-like type II cells envelop the type I cells and terminal axon enlargements, forming lobules which are embedded in connective tissue penetrated by a microvascular network of highly permeable sinusoidal capillaries. Fibroblasts, resident macrophages, and a small number of mast cells are also present in the tissue, together with post-ganglionic parasympathetic and sympathetic axons (McDonald 1981). According to the current view of low $\mathrm{O}_{2}$ - transduction, specialized $\mathrm{K}^{+}$channels close when ambient $\mathrm{O}_{2}$ decreases, initiating $\mathrm{Ca}^{2+}$ entry and excitatory neurotransmitter(s) release by type I cells. This leads to activation of chemoafferent neurons projecting to the nucleus tractus solitarius (NTS) of the medulla (Buckler,1999; Gonzalez et al. 1994).

Adaptation to $\mathrm{CH}$ involves remarkable morphological and physiological adjustments in the rat carotid body, including altered morphology, gene expression and increased chemosensitivity in the initial 1-3 days of exposure to hypobaric hypoxia (380 Torr) (Chen et al. 2002a; Chen et al. 2002b; Dinger et al. 2003). Such changes subsequently include elevated expression of vasoactive agents: vascular endothelial growth factor (VEGF), endothelin (ET), atrial natriuretic peptide (ANP) and nitric oxide (NO), which contribute to tissue remodeling and/or modified chemosensitivity (Chen et al. 2002a; Chen et al. 2002b; He et al. 1998; He et al. 2000; Dinger et al. 2003). Moreover, rat type I cells have been shown to increase $\mathrm{Na}^{+}$-channel $\left(\mathrm{Na}_{\mathrm{V}}\right.$ 1.1) expression in $\mathrm{CH}$, an adaptation which may contribute to enhanced cell depolarization and neurotransmitter release (Caceres et al. 2007). Adaptive changes to $\mathrm{CH}$ are also observed in chemoafferent neurons of the PG, which involve the expression of cholinergic receptors, and altered purinergic and cholinergic chemotransmission between type I cells and chemoafferent neurons (He et al. 2005; He et al. 2006). In addition, we have documented elevated expression of the gap-junction-forming protein, connexin-43 in type I cells and PG neurons (Chen et al. 2002b).

Given their exquisite sensitivity to oxygen, it has long been assumed that type I cells initiate and regulate adaptive processes via the autocrine and paracrine action of their secretory products. Consistent with this assumption, studies of these cells following $\mathrm{CH}$ have demonstrated phenotypic changes consistent with increased excitability (Bisgard 2000; Wang and Bisgard 2002). However, the alternate possibility that CH-induced adaptation involves other cell types in the carotid body has been virtually ignored. Moreover, little consideration has been given to the hypothesis that chemoreceptor adaptation is dependent on major changes in the excitability of chemoafferent neurons. 


\section{The Chronic Pain Model of Sensory Neuron Adaptation}

Amongst sensory systems, altered sensitivity in response to chronic stimulation is not unique to the carotid body. In fact, it has long been known that chronic inflammation or neuropathy induces chronic pain states characterized by hyperalgesia and allodynia. Within the last decade it has become widely recognized that nociceptor hyperexcitability involves unique neuroimmune mechanisms (Watkins and Maier 2002). Numerous studies of chronic pain have demonstrated that invading macrophages and neutrophils, as well as resident mast cells and dendritic cells induce remodeling and hypersensitivity of primary nociceptor neurons (Watkins and Maier 2002). In addition, mechanoreceptor neurons that do not normally signal pain initiate the production of "pain neurotransmitters" consequent to the action of inflammatory mediators (Neumann et al. 1996). Even cells which are not commonly associated with immune function may participate in the alteration of peripheral nerve function. For example, fibroblasts become a source of chemoattractant chemokine molecules [e.g., macrophage inflammatory protein-2 (MIP-2) and monocyte chemoattractant protein-1 (MCP-1)] that recruit circulating immune cells (primarily neutrophils and macrophages); this is followed by the production and secretion of proinflammatory cytokines (Watkins and Maier 2002). Numerous studies of chronic inflammatory and neuropathic pain consistently demonstrate up-regulation of three cytokines: interleukin-1 $\beta$ (Il-1 $\beta$ ), interleukin-6 (Il-6) and tumor necrosis factor- $\alpha(\mathrm{TNF}-\alpha)$, along with the chemokine, MCP-1 (Watkins and Maier 2002).

The growing body of evidence that supports a connection between immune cells and the development of altered tissue structure and hyperexcitability in chronic pain appears to provide a model for the role of immune cells and cytokines in altered carotid body structure, and the increased chemosensitivity in $\mathrm{CH}$. In an effort to follow this lead we have set forth to determine 1), whether $\mathrm{CH}$ induces an inflammatory condition in the carotid body, 2), the effect of common anti-inflammatory drugs on chemoreceptor adaptation, and 3), indications of $\mathrm{CH} /$ inflammation-induced phenotypic changes that are consistent with increased excitability in chemoafferent PG neurons.

\section{CH-Induced Immune Cell Invasion and Cytokine Expression in Carotid Body}

It is well known that immune cells express an isoform of the enzyme NADPH oxidase (Nox2) which uses $\mathrm{O}_{2}$ and the cofactor NADPH to produce reactive oxygen species (ROS) as part of a killing mechanism in tissues invaded by infectious microbes. Experiments in our laboratory established that Nox 2 and Nox 4 are increased in carotid body in $\mathrm{CH}$ (He et al. 2010). These findings may reflect increased Nox expression by resident cells in the organ and/or they may be due to invasion of activated immune cells, primarily monocytes and neutrophils. Circulating monocytes commonly differentiate into ED1+ macrophages following diapedesis. We used fluorescent immunocytochemistry to establish the timecourse of ED1+ cell activity in carotid body following 0,1,3 and 7 days of $\mathrm{CH} @ 380$ Torr (Liu et al. 2009). Figure 1 shows that ED1+ cells are rare in normal carotid body, and that their presence is only slightly increased following 1 day of $\mathrm{CH}$. However, following 3 days of $\mathrm{CH}$ the population of ED1+ cells is substantially elevated. After 7 days the incidence of macrophages remains high, but somewhat less than in organs from 3 day $\mathrm{CH}$ rats.

The increased presence of immune cells in the carotid body is correlated with elevated expression of inflammatory cytokines (Liu et al. 2009). Quantitative PCR studies (see figure 2 ) showed that $24 \mathrm{hr}$ of hypoxia elicited a $2-3$-fold increase in MCP-1, IL- $1 \beta$ and TNF $\alpha$. The lattermost cytokine remained at similar levels following 3 and 7 days of $\mathrm{CH}$, whereas IL-1 $\beta$ was equally elevated following 3 days, but fully recovered after 7 days. In contrast the 
chemoattractant chemokine, MCP-1 was further elevated beyond 6-fold after 3 days, and it remained at a similar level on day 7. CH induced a more gradual increase in IL-6 which was measured at $\sim 3$-fold and $\sim 2$-fold following 3 and 7 days of $\mathrm{CH}$, respectively. Interestingly, following 28 days of hypoxia the expression of inflammatory molecules was normal, with the exception of IL-6 which was some 5.5-fold above normal, suggesting that this latter cytokine may play a maintenance role in chemoreceptor adaptation. Support for the validity of the qPCR assays was provided by assessments of the mRNA transcript level of tyrosine hydroxylase (TH), which is known to increase in type I cells during $\mathrm{CH}$ (figure 2).

Additional studies in our laboratory showed that cytokine production was not limited to immune cells (Liu et al. 2009). Indeed, in situ hybridization experiments showed that IL-6 expression during $\mathrm{CH}$ is increased to high levels in putative type II cells, while a smaller but substantial elevation in probe signal was localized to cell clusters displaying morphology consistent with type I cells. We also used amplified RNA (aRNA) technology to demonstrate that $24 \mathrm{hr}$ of in vivo hypoxia elevated MCP-1, IL-1 $\beta$, TNF $\alpha$ and IL-6 in type I cells isolated in culture. These findings are in agreement with Lam et al. (Lam et al. 2008), who used immunocytochemical techniques to show elevated expression of inflammatory cytokines in type I cells following 7 days of $\mathrm{CH}$. These studies also support the concept that virtually all cells are capable of cytokine production (Oppenheim J J and Feldmann M, 2000).

\section{Effect of Anti-Inflammatory Drugs on Chemoreceptor Adaptation}

Studies of inflammatory pain in rats have shown that small doses of the common antiinflammatory drugs ibuprofen and dexamethasone prevent phenotypic changes associated with hyperexcitability in DRG neurons (O'Rielly and Loomis 2008; Huang et al. 2010; Voilley, et al. 2001; Teixeira et al. 2010). Ibuprofen is a well established non-selective inhibitor of cyclooxygenase 1 and 2 (COX1 and COX2)(Rainsford 2003). In addition, this drug has been shown to block the nuclear translocation of the transcription factor, nuclear factor kappa beta (NF- $\kappa \beta$ ), which mediates cytokine production including IL-1 $1 \beta$, TNF $\alpha$ and IL-6 (Scheuren et al. 1998). A potentially important physical property of ibuprofen is its tendency to partition into low $\mathrm{pH}$ compartments, such as local areas of inflammation (Brune and Lanz 1985; Brune et al. 1976). The steroid, dexamethasone, operates via nuclear receptors to block the cascade of cytokine synthesis and release. Studies have shown that dexamethasone blocks the early inflammation-induced release of IL-1 $\beta$ and TNF $\alpha$ (Haynes 1990). IL-6 production is also suppressed at least in part due to its dependence on the actions of IL-1 $\beta$ and TNF $\alpha$ (Haynes 1990).

Figure 3 shows hypoxia-evoked chemoreceptor discharge recorded in carotid body-CSN preparations superfused in vitro. The upper panel demonstrates the effect of $\mathrm{CH}$ on carotid body excitability in a side-by-side comparison of integrated nerve activity in a normal versus 9-day $\mathrm{CH}$ preparation. Following $\mathrm{CH}$, the activity evoked by a standardized acute hypoxic stimulus (bath $P_{\mathrm{O}_{2}}$ recorded via separate trace) is approximately doubled, as indicated in the summary histogram of 4 preparations. The middle and lower panels show the effect of concurrent administration of ibuprofen $(4 \mathrm{mg} / \mathrm{kg} /$ day, i.p. $)$ or dexamethasone $(0.1 \mathrm{mg} / \mathrm{kg} /$ day, i.p.) in non-hypoxic (normal) and $\mathrm{CH}$ animals. The results indicate that treatment with the anti-inflammatory drugs during $\mathrm{CH}$ completely blocks chemoreceptor adaptation.

Parallel studies evaluated the effect of these anti-inflammatory drugs on cytokine expression in the carotid body. The data in figure 4A indicate that ibuprofen inhibits more than $50 \%$ of the increase in expression of MCP-1, TNF $\alpha$ and IL- 6 induced by 7 days of $\mathrm{CH}$. As shown in figure 2 , IL-1 $\beta$ expression is fully recovered at this time point, and the presence of ibuprofen had no significant effect on the expression of this cytokine. It is also noteworthy that 
ibuprofen did not significantly alter $\mathrm{CH}$-induced up-regulation of TH mRNA, suggesting that this phenomenon occurs independently of the inflammatory response. In contrast, the increase in $\mathrm{TH}$ expression was enhanced during $\mathrm{CH}$ in animals treated with dexamethasone (figure 4B), a finding which concurs with previously demonstrated effects of this drug on normal carotid body (Hanbauer 1976). Moreover, this steroid potently blocked expression of all cytokines, even lowering IL-1 $\beta$ to a level slightly below normal.

Confirmation of the drug effects on immune cell activity was achieved by evaluating the inmmunostaining intensity of immune specific antigen CD45 in carotid body. Virtually all immune cells express this antigen which is known to be increased in inflamed tissue. The images in figure 5 show that the low CD45 intensity (green) in normal carotid body is substantially enhanced in tissue from a 3-day $\mathrm{CH}$ rat. Immunostaining for $\mathrm{TH}$ (red) is also greatly elevated in the $\mathrm{CH}$ tissue. Treatment with ibuprofen $(4 \mathrm{mg} / \mathrm{kg} /$ day $)$ or dexamethasone $(0.1 \mathrm{mg} / \mathrm{kg} / \mathrm{day})$ lowered CD45 expression in normal tissue, and eliminated the increase induced by $\mathrm{CH}$. Consistent with qPCR assays, increased immunostaining for $\mathrm{TH}$ following $\mathrm{CH}$ was not altered by ibuprofen, but it appeared to be slightly elevated by treatment with dexamethasone in both normal and $\mathrm{CH}$ tissue.

\section{Inflammation and Primary Sensory Neuron Excitability}

Numerous studies have shown that inflammation in the terminal fields of peripheral nerves induces phenotypic changes in primary sensory neurons, leading to enhanced excitability. Behavioral assessments have consistently demonstrated lowered mechanical and thermal stimulus thresholds and decreased latencies for reflexes elicited from inflamed peripheral fields. These changes have been correlated with altered gene and/or protein expression in corresponding DRG sensory neurons. Amongst the up-regulated genes are those coding for specialized transduction/receptor molecules, including ATP-gated purinergic receptors $\left(\mathrm{P} 2 \mathrm{X}_{\mathrm{N}}\right.$ ) (Barclay et al. 2002; Jarvis 2010), acid sensitive ion channels (ASICs) (Mamet et al. 2002; Voilley et al. 2001), and the multimodal transient receptor potential vallinoid-1 (TRPV1) receptor, which is sensitive to temperature, $\mathrm{pH}$ and selected chemical stimuli(Stucky et al. 2009). Importantly, pharmacological manipulations which block inflammation-induced expression of transducer molecules, also decrease the associated hyperalgesia and allodynia (Voilley et al. 2001; Barclay et al. 2002).

In addition to the altered expression of transducer molecules, numerous studies by Waxman and his colleagues (Cummins et al. 2007) have shown that inflammation induces altered expression of selected proteins that comprise voltage-gated $\mathrm{Na}^{+}$-channels (VGSC or $\mathrm{Na}$ ), which are generally responsible for the rapid up-stroke of the action potential in peripheral axons. VGSC consist of $\alpha$ - and $\beta$-subunits, with the latter serving a supporting role as stabilizers and modulators of $\alpha$-subunit function. Thus specific channel properties, including gating, kinetics and conductance are determined primarily by 9 isoforms of the $\alpha$-subunit found in mammals (Cummins et al. 2007). Molecular analysis has revealed that primary sensory neurons in DRG express at least $5 \alpha$-subtypes including the tetrodotoxin (TTX)sensitive $\mathrm{Na}_{V} 1.1, \mathrm{Na}_{V} 1.6, \mathrm{Na}_{V} 1.7$; and the TTX-resistant $\mathrm{Na}_{V} 1.8$ and $\mathrm{Na}_{V} 1.9$ (Waxman et al. 2000). Models of neuropathic pain (e.g., peripheral axotomy; nerve constriction) have shown down-regulation of $\mathrm{Na}_{\mathrm{v}} 1.8$ and $\mathrm{Na}_{\mathrm{v}} 1.9$, and the induced expression of a previously silent TTX-sensitive (TTX-S) channel, Nav1.3 (Waxman, et al. 2000). In contrast, a recent study of inflammatory pain (subcutaneous carrageenan injection) revealed a different pattern of $\mathrm{Na}^{+}$-channel expression in which $\mathrm{Na}_{\mathrm{V}} 1.3, \mathrm{Na}_{\mathrm{V}} 1.7$ and $\mathrm{Na}_{\mathrm{V}} 1.8$ are selectively increased in small ( $<30 \mu \mathrm{m})$ DRG neurons (Black et al. 2004). Electrophysiological assessments of sensory neurons have demonstrated altered action potential characteristics consistent with increased excitability, suggesting that modified expression of $\mathrm{Na}^{+}$-channels is a critical factor in hyperalgesia (Waxman et al. 2000). The fact that administration of nerve growth 
factor (NGF) and glial-derived neurotrophic factor (GDNF) prevent hyperexcitability following nerve injury supports the hypothesis that altered channel expression is due to the failure of retrograde axonal transport of growth factors in damaged axons (Waxman et al. 2000; Leffler et al. 2002). On the other hand, phenotypic changes in $\mathrm{Na}^{+}$-channel expression in inflammation may be due to elevated levels of NGF and other mediators released near inflamed nerve terminals (Black et al. 2004; Frostick et al. 1998). A particularly relevant observation is that concurrent treatment with ibuprofen reduces inflammation-induced hyperalgesia as well as expression of $\mathrm{Na}_{\mathrm{V}} 1.7$ and $\mathrm{Na}_{\mathrm{V}} 1.8$ (Gould et al. 2004).

Donnelly and his colleagues explored the properties of voltage-sensitive $\mathrm{Na}^{+}$-currents in rat PG neurons which were back-labeled with a fluorescent dye applied to the carotid body (Cummins et al. 2002). These authors reported that in $~ 80 \%$ of chemoafferent neurons $>95 \%$ of the $\mathrm{Na}^{+}$-current was TTX-sensitive. Moreover, detailed analysis of current kinetics indicated the involvement of $\mathrm{Na}_{\mathrm{V}} 1.7$, along with $\mathrm{Na}_{\mathrm{V}} 1.1$ and/or $\mathrm{Na}_{\mathrm{V}} 1.6$. These findings concur with a previous study showing that spontaneous activity generated in the terminals of rat carotid chemoreceptors is highly sensitive to TTX (Donnelly et al. 1998).

We recently initiated a preliminary study of the effect of $\mathrm{CH}$ on $\mathrm{Na}^{+}$-channel expression, and voltage-sensitive $\mathrm{Na}^{+}$-current in PG neurons. Consistent with reports that inflammation up-regulates $\mathrm{Na}_{\mathrm{V}}$ expression (Black et al. 2004), our immunocytochemical data shown in figure 6 demonstrate increased $\mathrm{Na}_{\mathrm{V}}$ staining intensity in PG neurons following 3 days of $\mathrm{CH}$. These images were produced using a pan-specific antibody which recognizes all $\alpha$ isoforms. Indication of specific $\mathrm{Na}_{\mathrm{V}}$ involvement is suggested in figure 7, which shows that 3 days of $\mathrm{CH}$ elicits an approximately 16-fold increase in expression of Nav1.7 transcript in the PG. Note that the transcript level was normal following 1 day of hypoxia, consistent with the possibility that increased expression involves retrograde signaling from the carotid body.

In a 2004 study, Black, et al., demonstrated that hyperalgesia elicited by peripheral inflammation is correlated with increased $\mathrm{Na}^{+}$-current density in small diameter $(\leq 25 \mu \mathrm{m})$ DRG neurons(Black et al. 2004). In similarly sized PG neurons we have found that $\mathrm{Na}^{+}-$ currents are likewise increased following 4-5 days of $\mathrm{CH}$. The family of membrane current traces shown in figure 8 were obtained using a holding potential of $-120 \mathrm{mV}$, and currents were evoked by $20 \mathrm{msec}$ voltage steps $(5 \mathrm{mV})$ to potentials between $-80 \mathrm{mV}$ and $+40 \mathrm{mV}$. Measurement of peak current amplitude indicates a 50\% increase following $\mathrm{CH}$ (fig. 8, lower panel). In view of these findings it is intriguing that Waxman and his colleagues proposed that the unique kinetic properties of $\mathrm{Na}_{\mathrm{V}} 1.7$ make it a candidate for activation in response to the slow depolarization elicited by chemical, mechanical and/or thermal stimuli in sensory nerve terminals (Cummins et al. 1998; Cummins et al. 2007). Moreover, selective knock-out of $\mathrm{Na}_{\mathrm{V}} 1.7$ in a subpopulation of small diameter neurons resulted in decreased thermal and mechanical hypersensitivity induced by inflammation (Nassar et al. 2004). Consequently, increased expression of this isoform may, in part, underlie the observed hyperexcitability in nociceptors, as well as chemoreceptors, following inflammation. A more complete understanding of the role of inflammation in altered $\mathrm{Na}^{+}$-channel expression will come with an evaluation of the effect of anti-inflammatory drugs on $\mathrm{Na}_{\mathrm{V}}$ transcript levels and $\mathrm{Na}^{+}$-currents in chemoafferent neurons. In addition, a role for $\mathrm{Na}^{+}$-currents may be further defined by examining the effects of $\mathrm{CH}$ on chemoreceptor adaptation in selected $\mathrm{NaV}$ gene-deleted animals.

\section{The Chemoafferent Pathway and Inflammation: Future Directions}

Our recent studies have expanded upon earlier work which demonstrated that oxygensensitive type I cells in the carotid body express cytokine receptors, and that $\mathrm{CH}$ elicits cytokine expression in the organ (Shu et al. 2007; Wang et al. 2002; Wang et al. 2006; Lam 
et al. 2008; Fan et al. 2009). The extent of neuroimmune involvement in $\mathrm{CH}$ was further elucidated by documenting immune cell invasion, and examining the effects of antiinflammatory drugs on adaptation. These findings may have implications for the use of common anti-inflammatory agents in the treatment of COPD and chronic heart failure, in addition to their use at high altitude.

Major unresolved issues remain for future investigations of inflammation-mediated chemoreceptor adaptation. At this writing virtually nothing is known about the cellular mechanisms which trigger immune cell invasion and the up-regulation of cytokines. Because of their exquisite sensitivity to hypoxia, it is likely that type I cells are involved in signaling the immune response. As noted earlier, type I cells are highly adaptive to $\mathrm{CH}$; it is likely that following the initial immune response, cytokines and their receptors participate in altering the functional status of type I cells. In this regard, it is important to note that previous studies of type I cell adaptation have demonstrated the involvement of hypoxia inducible factor-1 (HIF-1), a transcription factor known to be up-regulated by cytokines in multiple cell types (Hellwig-Burgel et al. 2005).

In addition, it appears that the full extent of adaptation involves significant changes in the functional status of primary chemoafferent neurons, particularly the expression of specific receptor molecules in nerve terminals. Moreover, animal models of chronic pain indicate that plasticity of the neuronal phenotype is influenced by local and retrograde signaling of neurotrophic factors produced in inflamed targets (Malin et al. 2006; Cummins et al. 2007). Therefore, important regulatory mechanisms may be elucidated by investigating the production and dynamics of selected factors in the inflamed carotid body. Finally, it is well established that inflammation and neuropathy in common peripheral nerves initiate complex changes within the dorsal horn of the spinal cord, including activation of microglia and the up-regulation of inflammatory cytokines. The resulting central sensitization is critical for the full development of hyperalgesia and allodynia (Woolf 2010). Important recent studies have demonstrated that similar mechanisms operating in the central terminal nucleus of the trigeminal cranial nerve, likewise mediate enhanced pain states (Okada-Ogawa et al. 2009; Fan et al. 2010; Xie et al. 2007). Thus the studies of Popa, et al.(Popa et al. 2011), which imply that central amplification of chemoreflex signaling following $\mathrm{CH}$ is blocked by ibuprofen, may further implicate the involvement of unique neuroimmune mechanisms in areas of the nucleus tractus solitarius (NTS) that control breathing.

\section{Acknowledgments}

Supported by USPHS grant HL 086508 in the USA, and in Spain, BFU2007-61848 (DGICYT), CIBER CB06/06/0050 (FISS-ICiii) and JCyL-GR242.

\section{Reference List}

Barclay J, Patel S, Dorn G, Wotherspoon G, Moffatt S, Eunson L, Abdel'al S, Natt F, Hall J, Winter J, Bevan S, Wishart W, Fox A, Ganju P. Functional downregulation of P2X3 receptor subunit in rat sensory neurons reveals a significant role in chronic neuropathic and inflammatory pain. J Neurosci. 2002; 22:8139-8147. [PubMed: 12223568]

Bisgard GE. Carotid body mechanisms in acclimatization to hypoxia. Resp Physiol. 2000; 121:237246.

Black JA, Liu S, Tanaka M, Cummins TR, Waxman SG. Changes in the expression of tetrodotoxinsensitive sodium channels within dorsal root ganglia neurons in inflammatory pain. Pain. 2004; 108:237-247. [PubMed: 15030943]

Brune, K.; Lanz, R. Pharmacokinetics of non-steroidal anti-inflammatory drugs. In: Bonta, IL.; Bray, MA.; Parnham, MJ., editors. Handbook of Inflammation. Vol. 5. Elsiever Science Publisheres; Amsterdam: 1985. p. 413-449. 
Brune K, Graf P, Glatt M. Inhibition of prostaglandin synthesis in vivo by nonsteroid antiinflammatory drugs: evidence for the importance of pharmacokinetics. Agents Actions. 1976; 6:159-164. [PubMed: 7934]

Buckler KJ. Background leak $\mathrm{K}^{+}$-currents and oxygen sensing in carotid body type 1 cells. Resp Physiol. 1999; 115:179-187.

Caceres AI, Obeso A, Gonzalez C, Rocher A. Molecular identification and functional role of voltagegated sodium channels in rat carotid body chemoreceptor cells. Regulation of expression by chronic hypoxia in vivo. J Neurochem. 2007; 102:231-245. [PubMed: 17564680]

Chen J, He L, Dinger B, Stensaas L, Fidone S. Role of endothelin and endothelin A-type receptor in physiological adaptation of the carotid body during chronic hypoxia. Am J Physiol Lung Cell Molec Physiol. 2002a; 282:L1314-L1323. [PubMed: 12003788]

Chen J, He L, Dinger B, Stensaas L, Fidone S. Chronic hypoxia upregulates connexin43 expression in rat carotid body and petrosal ganglion. J Appl Physiol. 2002b; 92:1480-1486. [PubMed: 11896013]

Cummins TR, Dib-Hajj SD, Waxman SG, Donnelly DF. Characterization and developmental changes of $\mathrm{Na}+$ currents of petrosal neurons with projections to the carotid body. J Neurophysiol. 2002; 88:2993-3002. [PubMed: 12466424]

Cummins TR, Howe JR, Waxman SG. Slow closed-state inactivation: a novel mechanism underlying ramp currents in cells expressing the hNE/PN1 sodium channel. J Neurosci. 1998; 18:9607-9619. [PubMed: 9822722]

Cummins TR, Sheets PL, Waxman SG. The roles of sodium channels in nociception: Implications for mechanisms of pain. Pain. 2007; 131:243-257. [PubMed: 17766042]

Dinger, B.; He, L.; Chen, J.; Stensaas, L.; Fidone, S. Mechanisms of morphological and functional plasticity in the chronically hypoxic carotid body. In: Lahiri, S.; Semenza, G.; Prabhakar, N., editors. Oxygen Sensing: Responses and Adaptation to Hypoxia. Marcel Dekker; New York: 2003. p. 439-465.

Donnelly DF, Panisello JM, Boggs D. Effect of sodium perturbations on rat chemoreceptor spike generation: implications for a Poisson model. J Physiol. 1998; 511 ( Pt 1):301-311. [PubMed: 9679183]

Fan J, Zhang B, Shu HF, Zhang XY, Wang X, Kuang F, Liu L, Peng ZW, Wu R, Zhou Z, Wang BR. Interleukin-6 increases intracellular $\mathrm{Ca} 2+$ concentration and induces catecholamine secretion in rat carotid body glomus cells. J Neurosci Res. 2009; 87:2757-2762. [PubMed: 19396873]

Fan W, Huang F, Zhu X, Dong W, Gao Z, Li D, He H. Involvement of microglial activation in the brainstem in experimental dental injury and inflammation. Arch Oral Biol. 2010; 55:706-711. [PubMed: 20621288]

Frostick SP, Yin Q, Kemp GJ. Schwann cells, neurotrophic factors, and peripheral nerve regeneration. Microsurgery. 1998; 18:397-405. [PubMed: 9880154]

Gonzalez C, Almaraz L, Obeso A, Rigual R. Carotid body chemoreceptors: from natural stimuli to sensory discharges. Physiol Rev. 1994; 74:829-898. [PubMed: 7938227]

Gould HJ III, England JD, Soignier RD, Nolan P, Minor LD, Liu ZP, Levinson SR, Paul D. Ibuprofen blocks changes in $\mathrm{Na}$ v 1.7 and 1.8 sodium channels associated with complete Freund's adjuvantinduced inflammation in rat. J Pain. 2004; 5:270-280. [PubMed: 15219259]

Hanbauer I. Long-term regulatory mechanisms for tyrosine hydroxylase in sympathetic ganglia and carotid body. Adv Biochem Psychopharmacol. 1976; 15:475-489. [PubMed: 15426]

Haynes, RC. Adrenocorticotropic Hormone; Adrenocortical steroids and their synthetic analogs; Inhibitors of synthesis ans actions of adrenocortical hormones. In: Gilman, AG.; Rall, TW.; Nies, AS.; Taylor, P., editors. The Pharmacological Basis of Therapeutics. 8. Pergamon; New York: 1990. p. 1431-1462.

He L, Chen J, Dinger B, Fidone S. The involvement of multiple vasoactive agents in altered rat carotid body chemosensitivity induced by chronic hypoxia. Soc Neurosci Abstr. 1998; 24:375.

He L, Chen J, Dinger B, Stensaas L, Fidone S. Effect of chronic hypoxia on purinergic synaptic transmission in rat carotid body. J Appl Physiol. 2006; 100:157-162. [PubMed: 16357082]

He L, Dinger B, Fidone S. Effect of chronic hypoxia on cholinergic chemotransmission in rat carotid body. J Appl Physiol. 2005:98. in press. [PubMed: 16109834] 
He L, Dinger B, Fidone S. Cellular mechanisms involved in carotid body inhibition produced by atrial natriuretic peptide. Am J Physiol Cell Physiol. 2000; 278:C845-C852. [PubMed: 10751332]

He L, Liu X, Chen J, Dinger B, Stensaas L, Fidone S. Modulation of chronic hypoxia-induced chemoreceptor hypersensitivity by NADPH oxidase subunits in rat carotid body. J Appl Physiol. 2010; 108:1304-1310. [PubMed: 20185631]

Hellwig-Burgel T, Stiehl DP, Wagner AE, Metzen E, Jelkmann W. Review: hypoxia-inducible factor-1 (HIF-1): a novel transcription factor in immune reactions. J Interferon Cytokine Res. 2005; 25:297-310. [PubMed: 15957953]

Huang ZJ, Hsu E, Li HC, Rosner AL, Rupert RL, Song XJ. Topical Application of Compound Ibuprofen Suppresses Pain by Inhibiting Sensory Neuron Hyperexcitability and Neuroinflammation in a Rat Model of Intervertebral Foramen Inflammation. J Pain. 2010

Jarvis MF. The neural-glial purinergic receptor ensemble in chronic pain states. Trends Neurosci. 2010; 33:48-57. [PubMed: 19914722]

Lam SY, Tipoe GL, Liong EC, Fung ML. Chronic hypoxia upregulates the expression and function of proinflammatory cytokines in the rat carotid body. Histochem Cell Biol. 2008

Leffler A, Cummins TR, Dib-Hajj SD, Hormuzdiar WN, Black JA, Waxman SG. GDNF and NGF reverse changes in repriming of TTX-sensitive $\mathrm{Na}(+)$ currents following axotomy of dorsal root ganglion neurons. J Neurophysiol. 2002; 88:650-658. [PubMed: 12163518]

Liu X, He L, Stensaas L, Dinger B, Fidone S. Adaptation to chronic hypoxia involves immune cell invasion and increased expression of inflammatory cytokines in rat carotid body. Am J Physiol Lung Cell Mol Physiol. 2009; 296:L158-L166. [PubMed: 18978039]

Malin SA, Molliver DC, Koerber HR, Cornuet P, Frye R, Albers KM, Davis BM. Glial cell linederived neurotrophic factor family members sensitize nociceptors in vitro and produce thermal hyperalgesia in vivo. J Neurosci. 2006; 26:8588-8599. [PubMed: 16914685]

Mamet J, Baron A, Lazdunski M, Voilley N. Proinflammatory mediators, stimulators of sensory neuron excitability via the expression of acid-sensing ion channels. J Neurosci. 2002; 22:1066210670. [PubMed: 12486159]

McDonald, DM. Peripheral chemoreceptors: Structure-function relationships of the carotid body. In: Hornbein, TF., editor. Regulation of Breathing, Part I. New York-Basel: Marcel Dekker, Inc; 1981. p. 105-319.

Nassar MA, Stirling LC, Forlani G, Baker MD, Matthews EA, Dickenson AH, Wood JN. Nociceptorspecific gene deletion reveals a major role for Nav1.7 (PN1) in acute and inflammatory pain. Proc Natl Acad Sci USA. 2004; 101:12706-12711. [PubMed: 15314237]

Neumann S, Doubell TP, Leslie T, Woolf CJ. Inflammatory pain hypersensitivity mediated by phenotypic switch in myelinated primary sensory neurons. Nature. 1996; 384:360-364. [PubMed: 8934522]

O'Rielly DD, Loomis CW. Spinal nerve ligation-induced activation of nuclear factor kappaB is facilitated by prostaglandins in the affected spinal cord and is a critical step in the development of mechanical allodynia. Neuroscience. 2008; 155:902-913. [PubMed: 18617333]

Okada-Ogawa A, Suzuki I, Sessle BJ, Chiang CY, Salter MW, Dostrovsky JO, Tsuboi Y, Kondo M, Kitagawa J, Kobayashi A, Noma N, Imamura Y, Iwata K. Astroglia in medullary dorsal horn (trigeminal spinal subnucleus caudalis) are involved in trigeminal neuropathic pain mechanisms. $\mathrm{J}$ Neurosci. 2009; 29:11161-11171. [PubMed: 19741123]

Oppenheim, JJ.; Feldmann, M. Introduction to the role of cytokine in innate host defence and adaptive immunity. In: Oppenheim, JJ.; Feldmann, M., editors. Cytokine Reference. Elsevier; New York: 2000. p. 3-20.

Popa D, Fu Z, Go A, Powell FL. Ibuprofen blocks time-dependent increases in hypoxic ventilation in rats. Resp Physiol \& Neurobiol. 2011 this issue.

Powell FL, Milsom WK, Mitchell GS. Time domains of the hypoxic ventilatory response. Respir Physiol. 1998; 112:123-134. [PubMed: 9716296]

Rainsford KD. Discovery, mechanisms of action and safety of ibuprofen. IntJ Clin Pract Suppl. 2003:3-8. [PubMed: 12723739] 
Scheuren N, Bang H, Munster T, Brune K, Pahl A. Modulation of transcription factor NF-kappaB by enantiomers of the nonsteroidal drug ibuprofen. Br J Pharmacol. 1998; 123:645-652. [PubMed: 9517383]

Shu HF, Wang BR, Wang SR, Yao W, Huang HP, Zhou Z, Wang X, Fan J, Wang T, Ju G. IL-1beta inhibits IK and increases [Ca2+]i in the carotid body glomus cells and increases carotid sinus nerve firings in the rat. Eur J Neurosci. 2007; 25:3638-3647. [PubMed: 17610583]

Stucky CL, Dubin AE, Jeske NA, Malin SA, McKemy DD, Story GM. Roles of transient receptor potential channels in pain. Brain Res Rev. 2009; 60:2-23. [PubMed: 19203589]

Teixeira JM, Oliveira MC, Nociti FH Jr, Clemente-Napimoga JT, Pelegrini-da-Silva A, Parada CA, Tambeli $\mathrm{CH}$. Involvement of temporomandibular joint $\mathrm{P} 2 \mathrm{X} 3$ and $\mathrm{P} 2 \mathrm{X} 2 / 3$ receptors in carrageenan-induced inflammatory hyperalgesia in rats. Eur J Pharmacol. 2010; 645:79-85. [PubMed: 20558155]

Voilley N, de WJ, Mamet J, Lazdunski M. Nonsteroid anti-inflammatory drugs inhibit both the activity and the inflammation-induced expression of acid-sensing ion channels in nociceptors. J Neurosci. 2001; 21:8026-8033. [PubMed: 11588175]

Wang X, Wang BR, Duan XL, Zhang P, Ding YQ, Jia Y, Jiao XY, Ju G. Strong expression of interleukin-1 receptor type I in the rat carotid body. J Histochem Cytochem. 2002; 50:1677-1684. [PubMed: 12486091]

Wang X, Zhang XJ, Xu Z, Li X, Li GL, Ju G, Wang BR. Morphological evidence for existence of IL-6 receptor alpha in the glomus cells of rat carotid body. Anat Rec A Discov Mol Cell Evol Biol. 2006; 288:292-296. [PubMed: 16463381]

Wang ZY, Bisgard GE. Chronic hypoxia-induced morphological and neurochemical changes in the carotid body. Microscopy Research \& Technique. 2002; 59:168-177. [PubMed: 12384961]

Watkins LR, Maier SF. Beyond neurons: evidence that immune and glial cells contribute to pathological pain states. Physiol Rev. 2002; 82:981-1011. [PubMed: 12270950]

Waxman SG, Cummins TR, Dib-Hajj SD, Black JA. Voltage-gated sodium channels and the molecular pathogenesis of pain: a review. J Rehabil Res Dev. 2000; 37:517-528. [PubMed: 11322150]

Woolf CJ. Central sensitization: Implications for the diagnosis and treatment of pain. Pain. 2010

Xie YF, Zhang S, Chiang CY, Hu JW, Dostrovsky JO, Sessle BJ. Involvement of glia in central sensitization in trigeminal subnucleus caudalis (medullary dorsal horn). Brain Behav Immun. 2007; 21:634-641. [PubMed: 17055698] 

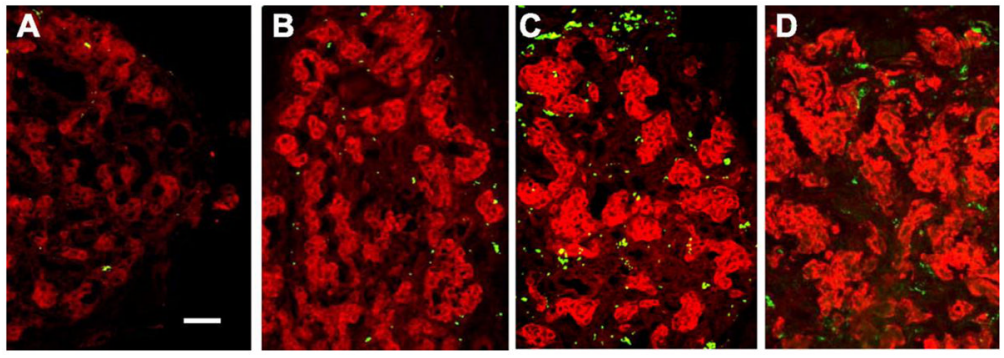

Figure 1.

Immunofluorescence in rat carotid body of type I cell marker tyrosine hydroxylase (red, $\mathrm{TH}$ ), and immune cell antigen ED1 (green). A: normal; B, C, and D: 1, 3 and 7 days of $\mathrm{CH}$, respectively. Scale bar: 50 um. (From Liu, He et al. 2009) 


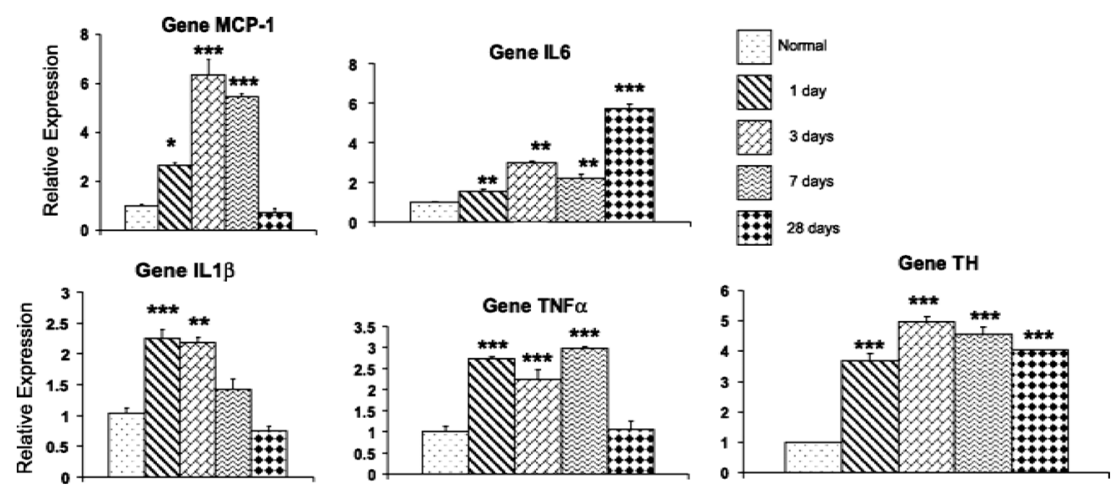

Figure 2.

Time course of chronic hypoxia $(\mathrm{CH})$-induced inflammatory cytokine, and tyrosine hydroxylase $(\mathrm{TH})$ gene expression in rat carotid body. Quantitative PCR data normalized to 18sRNA and expressed relative to mRNA levels in normal tissue. MCP-1: monocyte chemoattractant protein-1; IL6: interleukin-6; IL 1b: interleukin-1 $\beta$; TNFa: tumor necrosis factor- $\alpha . * * *$, and $* * *$ indicate $\mathrm{p}<0.05,0.01$ and 0.001 , respectively. $\mathrm{CH}$ : exposure at 380 Torr for time indicated. (From Liu, He et al. 2009) 

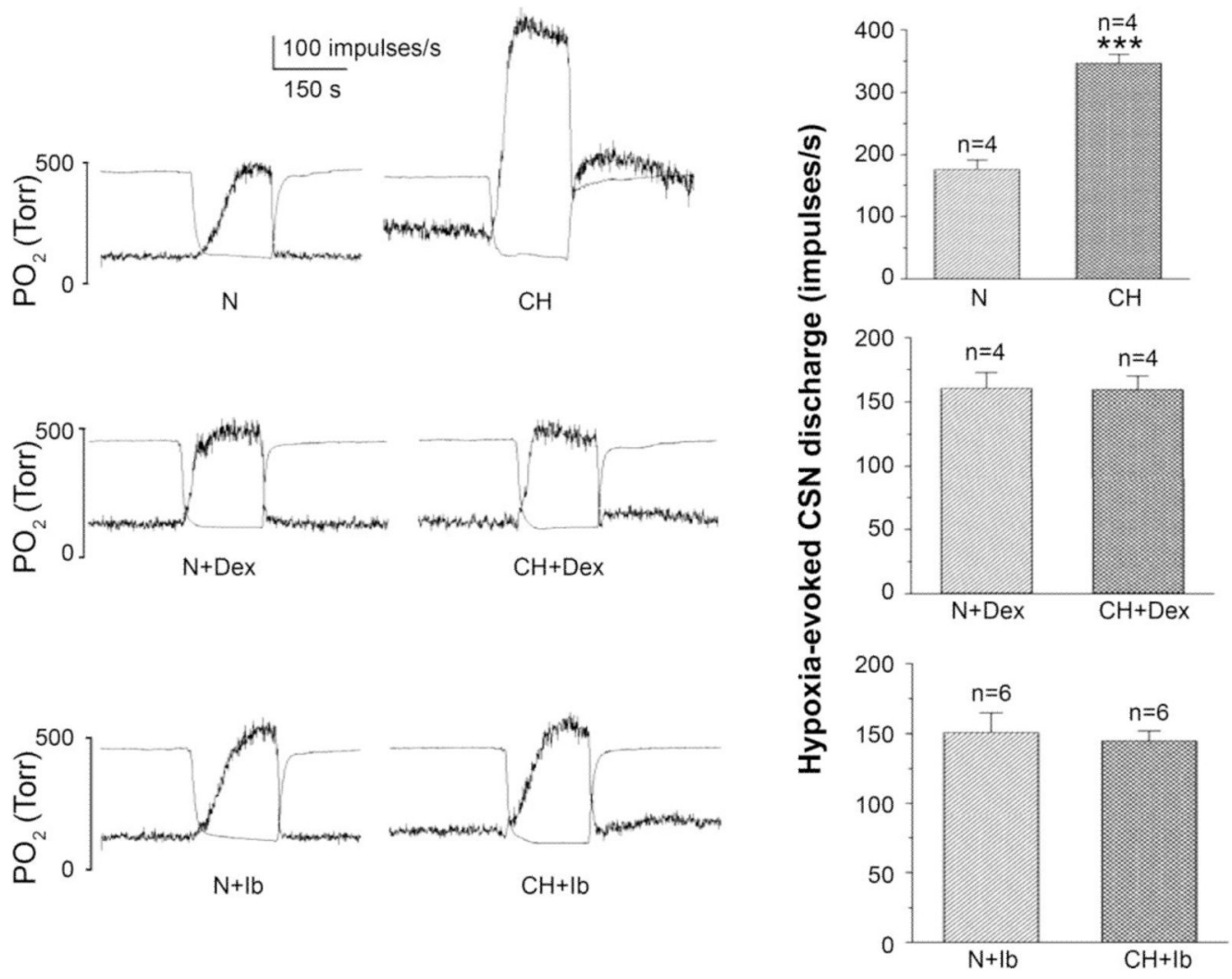

Figure 3.

Left panel: Carotid sinus nerve activity evoked by a standard hypoxic stimulus (indicated by separate trace of bath $\left.\mathrm{PO}_{2}\right)$ in normal $(\mathrm{N})$ vs. 8-10 day chronic hypoxia $(\mathrm{CH})$ preparations. $\mathrm{CH}$ elicits a robust increase in hypoxic sensitivity and basal resting activity; however, note that hypersensitivity to hypoxic challenge is absent in $\mathrm{CH}$ animals concurrently treated with dexamethasone (Dex; $0.1 \mathrm{mg} / \mathrm{kg} / \mathrm{day}$ ), or ibuprofen ( $\mathrm{Ib} ; 4 \mathrm{mg} / \mathrm{kg} / \mathrm{day})$. Right panel:

Summary data (averaged evoked impulses/sec) from 4 or 6 preparations in each group: drug free (upper) or concurrently treated with either dexamethasone or ibuprofen (middle and lower). *** indicates p $<0,001$ vs. normal. (From Liu, He et al. 2009) 

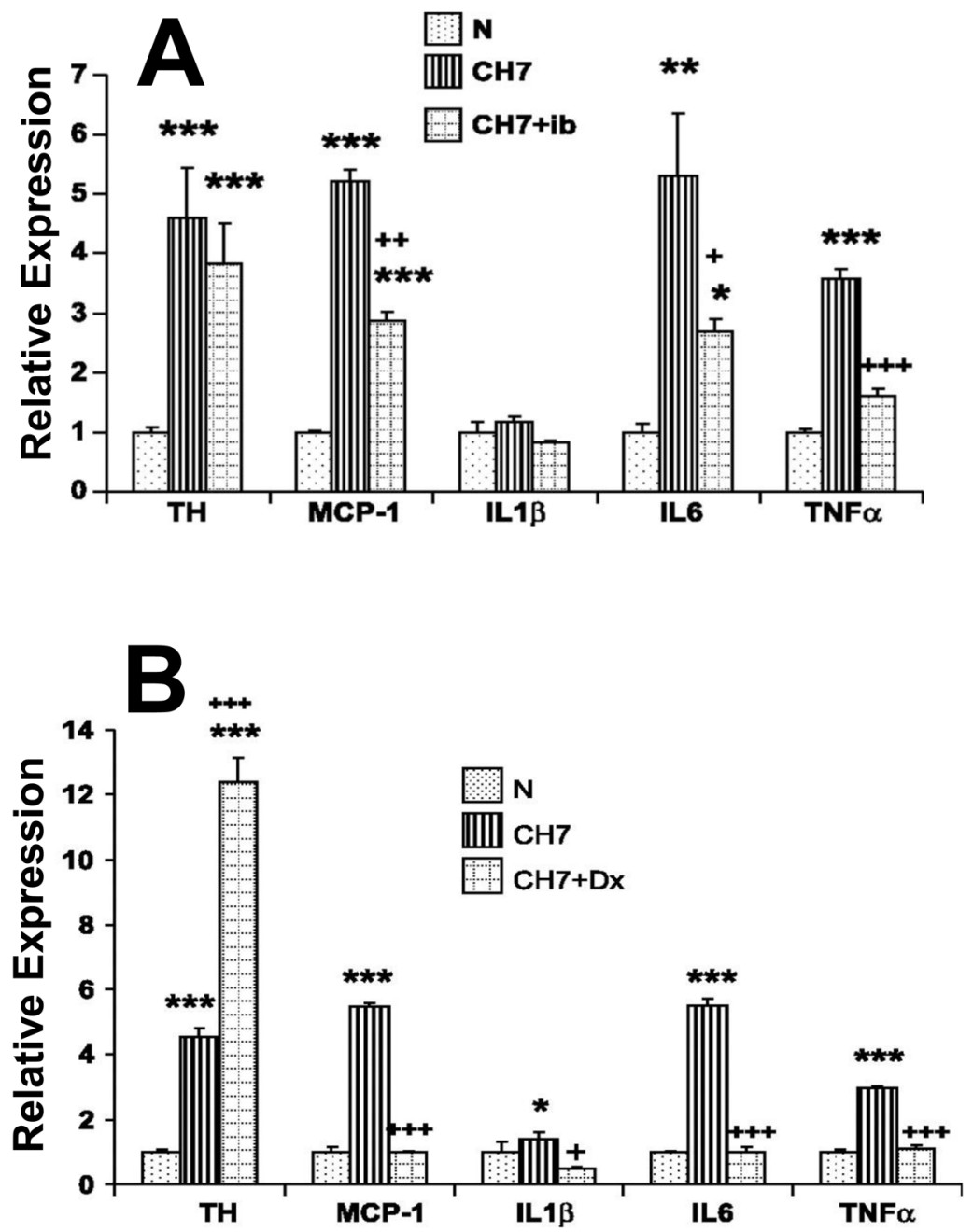

Figure 4.

Effect of ibuprofen, A, (ib; $4 \mathrm{mg} / \mathrm{kg} /$ day) or dexamethasone, B, (DX; $0.1 \mathrm{mg} / \mathrm{kg} /$ day) on 7 day $\mathrm{CH}$-induced gene expression of tyrosine hydroxylase and cytokines in rat carotid body. Abbreviations as in figure $2 . * * *$, and $* * *$ indicate $\mathrm{p}<0.05,0.01$, and 0.001 , respectively, vs. normal;,+++ , and $+++, \mathrm{p}<0.05,0.01$, and 0.001 , respectively, vs. 7 days CH. (Adapted from Liu, He et al. 2009) 

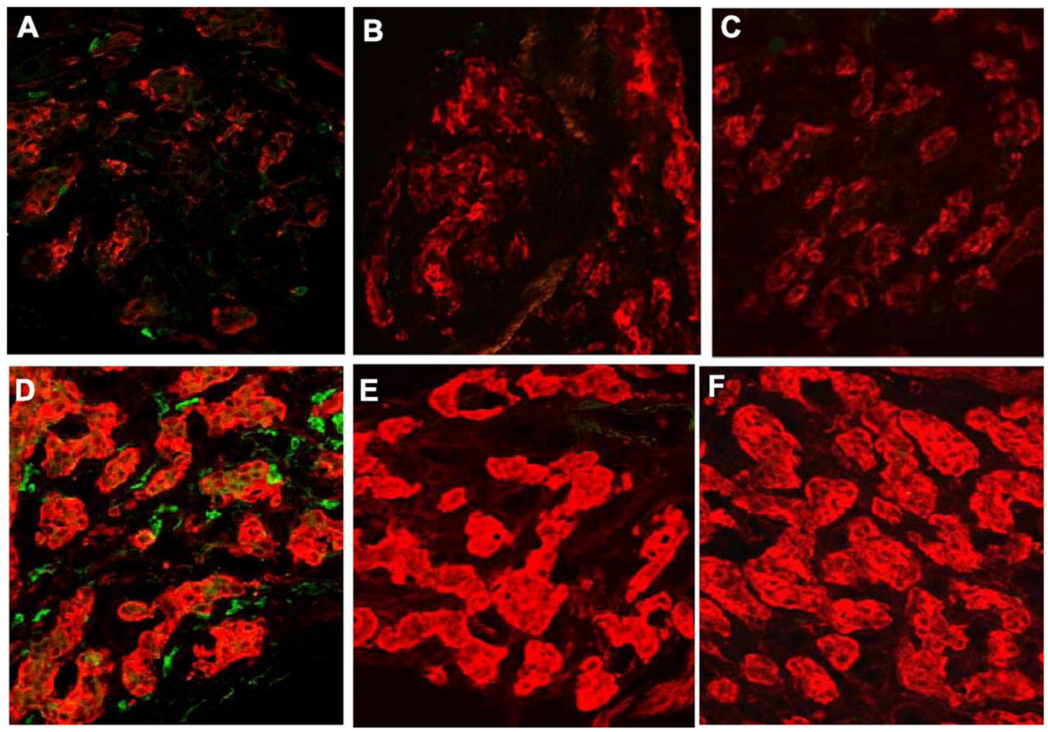

Figure 5.

Effect of anti-inflammatory drugs on $\mathrm{CH}$-induced immune cell activity in rat carotid body. Green cells are immunostained for CD45, a universal leukocyte marker; red indicates TH. (A) Normal carotid body contains a few immune cells that weakly express CD45. Following 3 days of $\mathrm{CH}(\mathrm{D})$ the tissue contains numerous cells which express higher levels of CD45. In normoxic carotid bodies from animals treated with dexamethasone $(0.1 \mathrm{mg} / \mathrm{kg} / \mathrm{day} ; \mathbf{B})$ or ibuprofen $(4 \mathrm{mg} / \mathrm{kg} / \mathrm{day} ; \mathbf{C})$ few or no detectable CD45+ immune cells are visible. Likewise, in $\mathrm{CH}$ animals treated with dexamethasone $(\mathbf{E})$ or ibuprofen $(\mathbf{F}), \mathrm{CD} 45+$ cells are virtually absent. Notice that TH fluorescence is increased in animals treated with dexamethasone. (From Liu, He et al. 2009) 

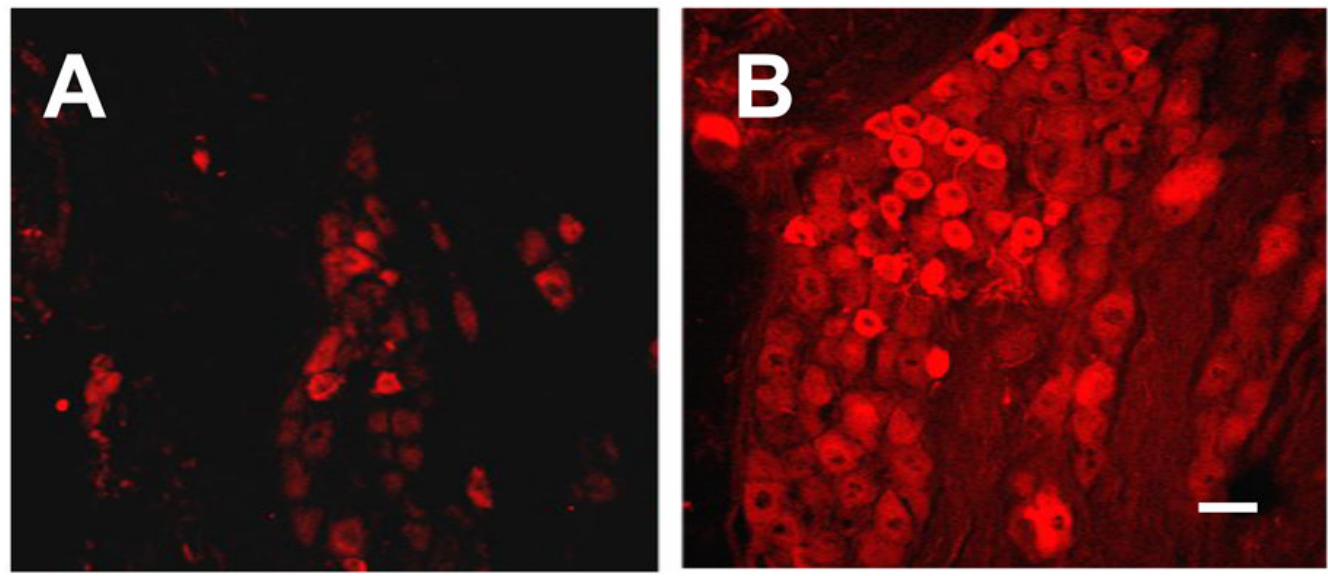

Figure 6.

Immunofluorescent assessment of $\mathrm{Na}+$-channel expression in petrosal (IXth nerve) ganglion from normal (A) and 3 day $\mathbf{C H}$ rats $(\mathbf{B})$. Formaldehyde-fixed frozen sections were immunostained with pan-specific antibody (Sigma, St. Louis, MO; product \#S6936) which recognizes all $\alpha-\mathrm{NaV}$ subunits. Scale bar, $30 \mathrm{um}$. 


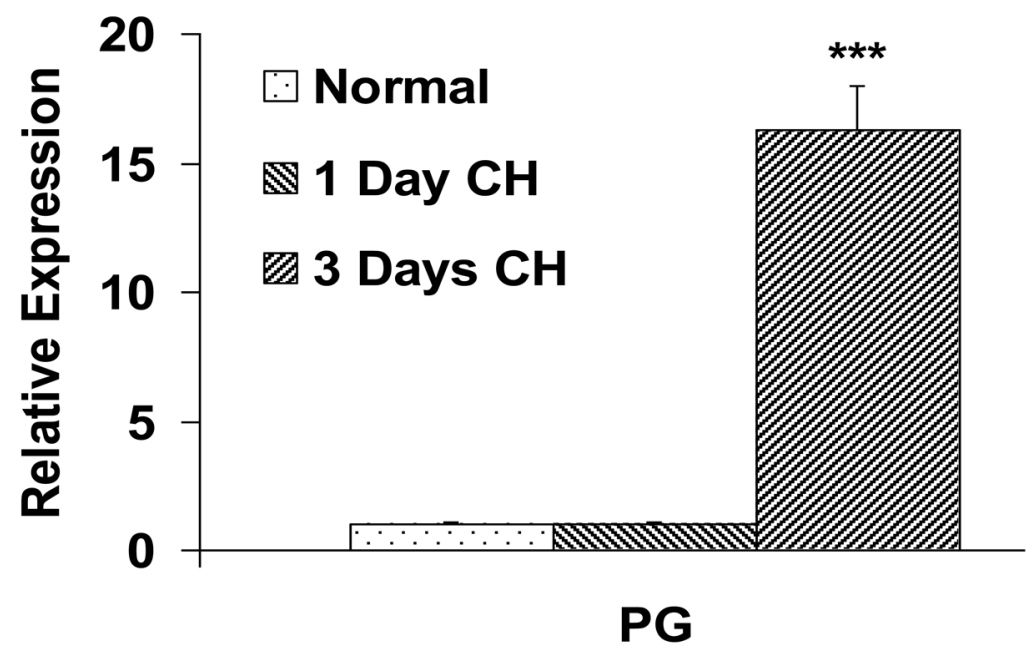

Figure 7.

Time course of chronic hypoxia $(\mathrm{CH})$-induced up-regulation of NaV1.7 $\alpha$-subunit of voltage gated Na+-channel. Quantitative PCR data normalized to 18sRNA and expressed relative to mRNA levels in normal tissue.

$* * *$ indicates $\mathrm{p}<0.001$. $\mathrm{CH}$ : exposure at 380 Torr for time indicated. 

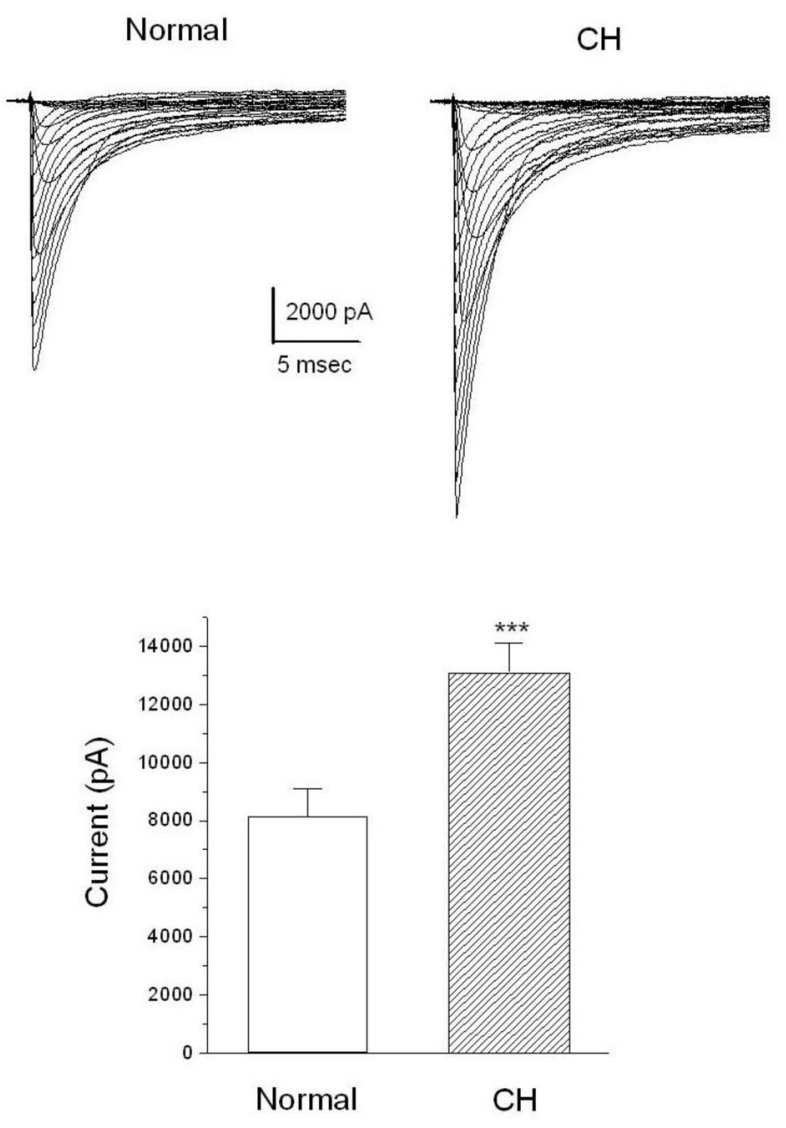

Figure 8.

Upper panel: Whole-cell patch clamp recording of family of Na+-currents in petrosal ganglion neurons $(\leq 25 \mu \mathrm{m})$ harvested from normal (left) and 5 day $\mathrm{CH}$ (380 Torr; right) adult male rats. Currents were evoked from a holding potential of $-120 \mathrm{mV}$ by $20 \mathrm{msec}$ steps $(5 \mathrm{mV})$ to potentials between $-80 \mathrm{mV}$ and $+40 \mathrm{mV}$.

Lower panel: Plot of peak current amplitude indicates a $50 \%$ increase following $\mathrm{CH}$. 